\title{
An ITER-relevant evacuated waveguide transmission system for the JET-EP ECRH project
}

\author{
M.A. Henderson ${ }^{1}$, S. Alberti ${ }^{1}$, J. Bird ${ }^{2}$, J. Doane ${ }^{3}$, B. Elzendoorn ${ }^{4}$, \\ C. Flemming ${ }^{2}$, T.P. Goodman ${ }^{1}$, F. Hoekzema ${ }^{5}$, J.P. Hogge ${ }^{1}$,

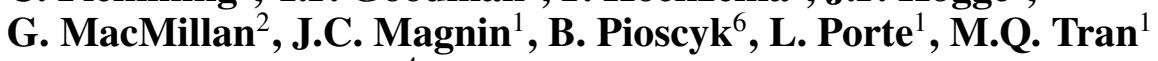 \\ and A.G.A. Verhoeven ${ }^{4}$ \\ ${ }^{1}$ Centre de Recherches en Physique des Plasmas, Association EURATOM-Confédération \\ Suisse, École Polytechnique Fédérale de Lausanne, CRPP-EPFL, 1015 Lausanne, \\ Switzerland \\ 2 EURATOM-JET UKAEA Culham \\ ${ }^{3}$ General Atomics-San Diego, CA, USA \\ ${ }^{4}$ EURATOM-FOM-Instituut voor Plasmafysica 'Rijnhuizen' \\ ${ }^{5}$ EURATOM-FZJ-Julich \\ ${ }^{6}$ EURATOM-FZK-Karlsruhe
}

Received 1 November 2002, accepted for publication 22 September 2003

Published

Online at stacks.iop.org/NF/43

\begin{abstract}
An over-moded evacuated waveguide line was chosen for use in the transmission system for the proposed JET-enhanced performance project (JET-EP) electron cyclotron resonance heating (ECRH) system. A comparison between the quasi-optical, atmospheric waveguide and evacuated waveguide systems was performed for the project with a strong emphasis placed on the technical and financial aspects. The evacuated waveguide line was chosen as the optimal system in light of the above criteria. The system includes six lines of $63.5 \mathrm{~mm}$ waveguide for transmitting $6.0 \mathrm{MW}(10 \mathrm{~s})$ at $113.3 \mathrm{GHz}$ from the gyrotrons to the launching antenna. The designed lines are on average $72 \mathrm{~m}$ in length and consist of nine mitre bends, for an estimated transmission efficiency of $\sim 90 \%$. Each line is designed to include an evacuated switch leading to a calorimetric load, two dc breaks, two gate valves, one pumpout tee, a power monitor mitre bend and a double-disc CVD window near the torus. The location of waveguide support is positioned to minimize the power converted to higher-order modes from waveguide sagging and misalignment. The two gate valves and CVD window are designed to be used as tritium barriers at the torus and between the J1T and J1D buildings. The last leg of the waveguide leading to the torus has to be designed to accommodate the torus movement during disruptions and thermal cycles. All lines are also designed to be compatible with the ITER ECRH system operating at $170 \mathrm{GHz}$.
\end{abstract}

PACS numbers: $84.40 . \mathrm{Az}$

\section{Introduction}

A 6.0 MW electron cyclotron resonance heating (ECRH) system [1] has been under design for the JET-enhanced performance project (JET-EP). The ECRH system is designed specifically for controlling neo-classical tearing modes (NTMs) and for heating and current drive experiments in a variety of target plasma configurations [2]. The system includes six gyrotrons $(113.3 \mathrm{GHz}$ each at $1.0 \mathrm{MW}$ for $10 \mathrm{~s}$ or $0.6 \mathrm{MW}$ for $30 \mathrm{~s}$ ) located in the south side of the JET diagnostic hall (J1D), with an option of two additional gyrotrons at $170 \mathrm{GHz}$. The microwave power is to be transmitted to the JET torus via six evacuated waveguide transmission lines averaging $\sim 72 \mathrm{~m}$ in length [3]. A plug-in antenna assembly [4] is used to launch the power from the waveguide to the plasma. The antenna consists of eight launchers, with the last mirror of each launcher capable of steering two beams in both the toroidal and poloidal directions. Two of the eight launchers are spares or are reserved for potential procurement of two $170 \mathrm{GHz}$ gyrotrons. The launcher is designed for high power density, off-axis current drive for NTM stabilization along with heating, co- and counter-current drive on axis. The description of the launcher is not included as an element of the transmission line for the JET-EP ECRH project. 
The JET-EP ECRH system was planned to begin operation at the beginning of 2004, with the full $6.0 \mathrm{MW}$ available in 2005. Recently, the project was discontinued due to budget restrictions and is no longer planned to be installed. However, the conceptual design work for the transmission line system was nearly complete at the time of cancellation. The criteria that led to this design of the JET-EP ECRH transmission line are relevant for ECRH systems on future machines. The aim of this paper is to document some of the design choices for the benefit of those future ECRH systems. In particular, various transmission methods (evacuated waveguide, quasi-optical (QO) and atmospheric waveguide lines) have been investigated, with the principal designs explained in chronological order. The study concluded that the evacuated waveguide line had many advantages over other systems for the same cost. The design study also has implications for the ITER ECRH design including tritium barriers, a CVD window design, an in-line switching network and waveguide support systems such as ITER.

Each ECRH transmission line is designed for transmission of $>1.0 \mathrm{MW}$ at both 113.3 and $170 \mathrm{GHz}$ frequencies for pulsed operation $(10 \mathrm{~s}$, with $1 \%$ duty cycle). The dualfrequency operation is specified for potential addition of two $170 \mathrm{GHz}$ gyrotrons plus reuse of the waveguide components (all designed for $\mathrm{CW}$ operation) on the ITER-ECRH system. The gyrotrons, $\sim 40 \mathrm{~m}$ from the torus, are aligned in a single row on a platform to be built along the south side of the J1D hall (see figure 1). A matching optics unit (MOU, equivalent to the RF conditioning unit-RFCU for ITER) is attached to the output of each gyrotron. The MOU contains four mirrors, and the first and fourth mirrors transform the microwave beam in the $\mathrm{TEM}_{00}$ mode coming from the gyrotron to match the desired beam waist and location for coupling into the waveguide. The other two mirrors are grating polarizers, which form a universal polarizer ([5] and references included in this publication) capable of providing the necessary polarization for optimum coupling to the plasma at any injected launch angle. In addition the first mirror in the MOU is part of a grating mirror power monitor similar to the proposed grating mirror designed for use on the W7-X ECRH system [6]. Small grooves are to be machined on the mirror surface that will diffract a small amount RF power $(\sim 30 \mathrm{~dB})$ at a desired angle. The power in the diffracted beam will be coupled to a matched horn and detector providing an active signal of the delivered power to the torus. The inner surface of the MOU is coated with an absorbing layer, which absorbs any stray radiation coming from the output of the gyrotron. The transmission line is connected directly to the output of the MOU and includes all items from the MOU output up to the end of the waveguide, which is inserted into the launching antenna positioned in octant 1 on the east side of the JET torus. Six separate lines of $63.5 \mathrm{~mm}$ diameter corrugated waveguide are planned with the possibility to add two additional lines upon procurement of the $170 \mathrm{GHz}$ gyrotrons. The principle components of the transmission line include two dc breaks (providing electrical isolation of the line from the gyrotron and torus), nine mitre bends, a power monitor mitre bend (for monitoring forward and reflected power plus near real time measurement of the beam's polarization), a switching network (directs beam to load or launcher), a pumpout tee, a doubledisc CVD window (principle tritium barrier near torus) and two gate valves (for vacuum isolation of waveguide sections and tritium barriers in case of CVD window failure).

This paper describes the transmission line design; a more detailed description is available from [7]. From the onset of the project a $63.5 \mathrm{~mm}$ evacuated $H E_{11}$ waveguide

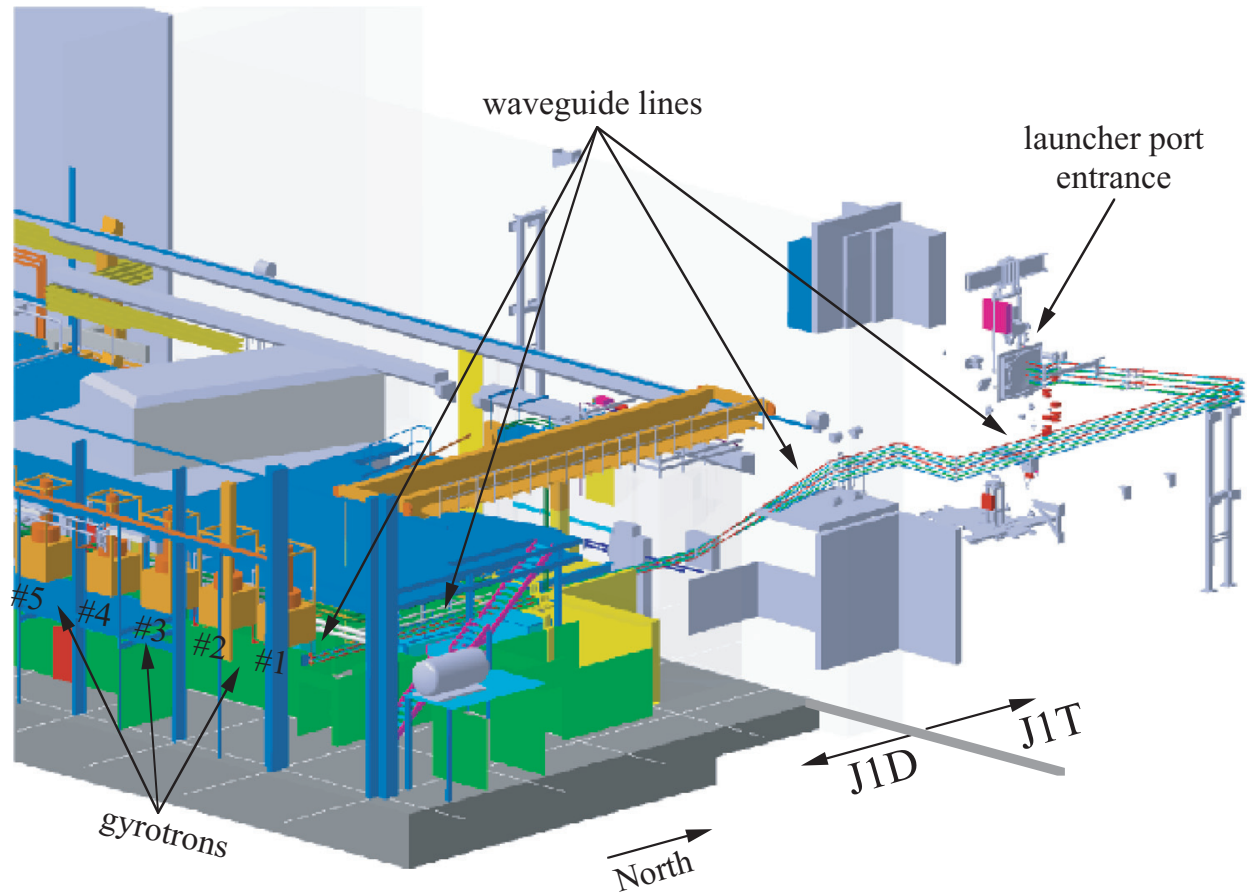

Figure 1. View of J1D and J1T halls including the gyrotrons (bottom left), waveguide lines and input to the JET torus. The waveguides coming from the gyrotrons run eastwards up to gyrotron \#1 before dropping down to a height of $>2.5 \mathrm{~m}$ above the ground floor. A mitre bend directs each line towards the barrier wall between J1D and J1T. In J1T the lines rise to a height of $7 \mathrm{~m}$ and follow the barrier wall (not shown) until opposite octant 1 , and then drop down to the launcher port. 
was planned to be used for the JET-EP ECRH transmission line [2]. Since then the choice of the transmission system has undergone several changes with the goal of finding the optimum system based on economics and security constraints imposed upon the design by the JET operator. Both the financial and technical constraints strongly influence the choice of transmission systems to be used on a fusion research device. Financially, evacuated waveguide lines have been viewed as an expensive method for transmitting high-power microwave beams to the plasma, offering a compact system but at a price higher than that of a QO system. Section 2 describes the transmission systems investigated for JET-EP with a strong influence on a detailed cost comparison between QO and evacuated waveguide systems. Monetary values are avoided due to fluctuations in currency rates and manufacturing prices; instead, prices are expressed as percentages relative to the cost of the previously proposed transmission system, a hybrid atmospheric $87 \mathrm{~mm}$ waveguide line in J1D and a QO line in J1T (WG87-QO). The percentages reflect the manufacturing and currency rates from August, 2002. The comparison concludes that the evacuated waveguide system offers many advantages (both economical and technical) over a QO system. Section 3 describes the design of the transmission line as it stood at the cancellation of the project. The design of a highpower microwave transmission system in an existing tokamak site encounters several hindrances from tritium handling to clearance for overhead crane passage; section 4 discusses some of these problems. Application of this design to other fusion devices is discussed in the conclusion, section 5.

\section{Optimizing the ECRH transmission system}

The originally planned transmission system for the JET-EP ECRH project had been an evacuated $63.5 \mathrm{~mm}$ diameter corrugated waveguide (WG63). However, evacuated waveguide lines were viewed as an expensive method for transmitting high-power microwave beams from the gyrotron to the plasma, in contrast to QO transmission lines, which are traditionally viewed as relatively inexpensive. A QO line was adopted for the JET-EP ECRH project after the JET operator expressed concerns that the WG63 might act as a channel for tritium from the torus to J1D. The operator placed the highest priority on minimizing the risks of a tritium leakage into J1D via the ECRH transmission line. There are two barriers, which prevent tritium from escaping from the torus and leaking into J1D: the torus vessel and the $\sim 4 \mathrm{~m}$ thick concrete barrier between J1D and J1T. The initial design using WG63 maintained the barrier at the torus wall using a double-disc CVD window (see section 4.2), but this barrier could be compromised in the event of both windows rupturing. Tritium could then flow through the waveguide up to the MOU and then out through the pumping station and into the hall J1D. The WG63 design could have been improved to avoid the risk of tritium leakage into J1D [8], but an estimated 30\% reduction in costs motivated a complete change in design philosophy towards a QO line. The cost reduction associated with the QO line was preliminary and based on reduced manufacturing costs of the QO mirrors relative to the costs of the precision machined corrugated waveguide elements in the WG63 line. Also, the WG63 design was nearly complete and included the costs of the auxilliary systems (supports, pumps, etc), while the QO system was preliminary and did not include the cost of all the auxilliary systems, some of which were to be later required by the JET operator.

With a QO line tritium would not be channelled to J1D if there was a failure in the CVD window on the torus. The barrier between J1D and J1T could be maintained with an additional CVD window between the two halls [9]. However, a complete QO line from the gyrotron to the torus had drawbacks. Shielding around the section of the line in J1D (required by the operator to avoid stray radiation) would occupy a considerable volume and obstruct the use of an overhead crane. All envisioned routings of the $\mathrm{QO}$ line in J1D were deemed unacceptable by the JET operator, which led to the development of a hybrid line of an atmospheric $87 \mathrm{~mm}$ waveguide line (WG87) in J1D and a QO line in J1T (WG87-QO) [10,11]. The atmospheric WG87 line prevented pumping of tritium from J1T to J1D and also avoided E-M radiation leakage into J1D. The electric field intensity in the large diameter $87 \mathrm{~mm}$ waveguide would be low enough to avoid a breakdown in the waveguide line. The additional CVD window between J1D and J1T was removed, and a constant flow of dry air from the MOU towards J1T minimized the risk of tritium up-streaming into the waveguide in the event of a tritium leak in J1T. The waveguide section of the WG87-QO was $\sim 30 \mathrm{~m}$ in length with four mitre bends and followed a route similar to that shown in figure 1. Two additional mitre bends were included to deviate the large sized waveguide around existing structures in J1D. The QO section consisted of nine mirrors in $\mathrm{J} 1 \mathrm{~T}$ and a seven mirror launching antenna inside the torus port. The WG87-QO was also relatively inexpensive compared with the price of the QO line, estimated at roughly $70 \%$ of a complete QO line. The difference in costs came about from removing the CVD window at the barrier between J1D and J1T. The WG87-QO was recommended by the design team $[12,13]$ as offering a relatively inexpensive system that satisfied the operator's requirements in J1T and J1D.

The initial cost comparison between the evacuated waveguide line and an equivalent $\mathrm{QO}$ line was a rough estimate for the total cost of the transmission systems up to but not including the CVD window unit. However, the double-disc CVD window units are relatively expensive, and the CVD window housing unit has a cost equivalent to the initially estimated price of the entire WG87-QO line. The propagation of a high-power RF beam in the atmosphere requires a large CVD disc to avoid breakdown on the surface of the window. The CVD discs for the evacuated waveguide line can be smaller and thus less expensive than those for the WG87-QO. For example, the two discs that are required for a single window unit of the WG87-QO can be cut into six smaller discs and used for three window units with evacuated $31.75 \mathrm{~mm}$ diameter corrugated waveguide (WG31). Furthermore, the discs for WG31 can be thinner (the smaller diameter window has lower pressure forces), reducing the price even further. The CVD window unit price for the WG31 is only $\sim 30 \%$ of the QO CVD window unit. Single discs of CVD diamond (cut from a large disc) have already been assembled into WG31 vacuum windows with Helicoflex ${ }^{\circledR}$ seals by General Atomics [14]. They are designed for $\sim 1.0 \mathrm{MW}$ transmission and have been installed on LHD for operation at 
Table 1. Present day $H E_{11}$ evacuated waveguide lines installed in JT-60U [19], DIII-D [20], LHD [21], Tore Supra [22], and TCV [23]. The table includes the waveguide diameter $\left(\Phi_{\mathrm{WG}}\right)$, maximum gyrotron output power $\left(P_{\text {gyro }}\right)$ and pulse lengths $(t)$, the number of lines with the number of mitre bends, overall line length and transmission efficiency.

\begin{tabular}{llllll}
\hline Device & $\Phi_{\mathrm{WG}}$ & $\begin{array}{l}P_{\text {gyro }}(\mathrm{MW}) / \\
(\mathrm{s})\end{array}$ & $\begin{array}{l}\text { lines/mitre } \\
\text { bends }\end{array}$ & $\begin{array}{l}\text { Length } \\
(\mathrm{m})\end{array}$ & $\begin{array}{l}\eta_{\text {line }} \\
(\%)\end{array}$ \\
\hline JT-60U & 31.75 & $1.0 / 2$ & $4 / 9$ & 53 & 81 \\
DIII-D & 31.75 & $1.0 / 5$ & $5 / 6-12$ & $50-95$ & 83.5 \\
LHD & 31.75 & $0.8 / 3$ & $1 / 10$ & 65 & \\
TS & 63.5 & $0.5 / 5$ & $2 / 5$ & 25 & \\
TCV & 63.5 & $0.5 / 2$ & $9 / 5$ & 30 & 95.9 \\
\hline
\end{tabular}

84 and $168 \mathrm{GHz}$. Other WG31 diamond windows with brazed seals have been installed on JT-60U for operation at $110 \mathrm{GHz}$ and on TRIAM-1M [15] for $170 \mathrm{GHz}$. WG31 is a common waveguide size used in several transmission systems currently in existence (DIII-D [16], JT-60U [17] and LHD [18]) with transmitted power levels up to $1.0 \mathrm{MW}$ (see table 1).

A preliminary cost study that included the CVD window unit estimated the WG31 waveguide line based on manufacturer prices at $\sim 20 \%$ less than the WG87-QO line. The smaller waveguide also simplified the launching antenna reducing the number of internal mirrors from seven to two. The WG31 design included a multiple barrier system in case of a tritium leakage at the CVD window, which was acceptable to the operator, similar to the system presented in section 4.1. In light of the financial savings, the improved tritium containment and the compactness of the evacuated waveguide system, a full design study was initiated that offered a comparison between the evacuated waveguide line and the WG87-QO line.

\subsection{Cost of the CVD window unit}

CVD discs for microwave applications are available from at least two sources in Europe. Recently, one supplier has begun offering smaller $75 \mathrm{~mm}$ diameter discs that are $\sim 23 \%$ of the price of a $106 \mathrm{~mm}$ disc. Smaller discs with uniform microwave absorption are less complicated (and likewise less expensive) to grow than the larger discs. Similar discs from the above supplier are currently in use on the $1.0 \mathrm{MW} 140 \mathrm{GHz}$ gyrotron [24] for the W7-X ECRH system [25]. The WG87-QO requires a $\sim 100 \mathrm{~mm}$ disc since a large beam with a lower power density is needed to avoid a breakdown on the atmospheric side and potential rupture of the disc. However, the less expensive smaller $75 \mathrm{~mm}$ discs could be used on either the WG31 or WG63 window units, thus significantly reducing the cost from the initial estimate for the WG63 at the start of the project.

The window on the output of the gyrotron is also required to use a CVD disc. The WG87-QO forces the gyrotron manufacturer to install a large diameter disc for the output window, increasing the cost of the gyrotron. A smaller diameter disc can be used with an evacuated waveguide line, offering a further reduction in the cost of the whole ECRH project, equivalent to $\sim 15 \%$ of the cost of an entire WG87-QO line for each gyrotron. This difference is not included in the cost comparison since it is reflected in the price of the gyrotron.
Table 2. Relative prices of the transmission line for the various waveguide diameters and the WG87-QO reference design. Actual values are avoided due to price and currency exchange rate fluxuations. The last row represents the cost of the waveguide line relative to the estimated price of the WG87-QO (based on prices from August, 2002).

\begin{tabular}{lrrrc}
\hline Component & $\begin{array}{l}\text { WG31 } \\
(\%)\end{array}$ & $\begin{array}{l}\text { WG45 } \\
(\%)\end{array}$ & $\begin{array}{l}\text { WG63 } \\
(\%)\end{array}$ & $\begin{array}{l}\text { WG87-QO } \\
(\%)\end{array}$ \\
\hline Mitre bend & 16 & 13 & 11 & 6 \\
Power monitor & 5 & 4 & 4 & \\
Waveguides & 13 & 20 & 20 & 12 \\
Pumpout tee & 3 & 3 & 3 & \\
dc break & 5 & 4 & 4 & 1 \\
Gate valves & 14 & 14 & 16 & 18 \\
Two pumping stations & 4 & 3 & 3 & \\
Switches & 18 & 17 & 19 & 5 \\
In-line bellows & & & 2 & 2 \\
QO mirrors & & & & 23 \\
CVD window unit & 22 & 18 & 17 & 34 \\
Total & 100 & 100 & 100 & 100 \\
Relative total & 71 & 88 & 90 & 100 \\
\hline
\end{tabular}

\subsection{Cost of the evacuated lines versus WG87-QO}

The comparison of the WG31 with the base design of the WG87-QO was expanded to include the waveguide diameters of $45 \mathrm{~mm}$ (WG45) and $63.5 \mathrm{~mm}$ (WG63), with the three evacuated waveguide lines following the same routing as shown in figure 1. A cost comparison between the three waveguide systems and the WG87-QO line is given in table 2 . Since the price of waveguide elements changes in time, the value is given as a percentage of the total cost of each line, as of August, 2002. The last row of the table represents the price of each system relative to the cost of the WG87-QO design $(\operatorname{cost}=1.00)$. The WG45 is a waveguide diameter not offered commercially but was included in the investigation as an optimum between the WG31 and WG63, which are commonly used waveguide sizes on existing ECRH systems around the world (see table 1). Waveguides with large diameters have lower power losses from mitre bends and Ohmic attenuation in the line, while the smaller diameter waveguides are more flexible, easily accommodating the torus displacements (see section 4.5). The WG45 was considered as the optimal diameter for the JET-EP project, and the diameter was small enough to accommodate the torus displacement, yet not too small for the increased waveguide losses.

\subsection{Transmission efficiency}

The power of an ECRH system should not be considered as the sum of the output powers measured at the window of each gyrotron but the power delivered to the plasma surface. From the gyrotron output window the beam will be attenuated in the MOU, the waveguide line and finally the launcher, with the lost power representing a hidden cost. The $H E_{11}$ waveguide losses [28] were calculated for the three evacuated waveguide diameters and the WG87-QO (see table 3). The total losses are calulated from the coupling into the waveguide up to the output of the launching antenna and include Ohmic attenuation, aperaturing of the beam and mode conversion from the $H E_{11}$. The WG87-QO and WG63 are nearly equivalent in the transmission efficiency, with total losses $<10 \%$. The losses 
Table 3. Total transmission losses for each waveguide diameter and WG87-QO. Seven mitre bends are used in the calculation for the losses in the evacuated waveguide line assuming avoiding the dogleg around the ventilation shaft (see section 3). The WG87-QO has four mitre bends. The WG31 and WG45 lines would use phase-correcting mirrors in the mitre bend.

\begin{tabular}{lccll}
\hline Type of loss & $\begin{array}{l}\text { WG31 } \\
(\%)\end{array}$ & $\begin{array}{l}\text { WG45 } \\
(\%)\end{array}$ & $\begin{array}{l}\text { WG63 } \\
(\%)\end{array}$ & $\begin{array}{l}\text { WG87-QO } \\
(\%)\end{array}$ \\
\hline Coupling into WG & 1.9 & 1.9 & 1.9 & 1.9 \\
$H E_{11}$ attenuation & 3.9 & 1.3 & 0.5 & 0.1 \\
Mitre bend losses & 6.8 & 4.7 & 4.1 & 1.6 \\
CVD reflections & 0.3 & 0.3 & 0.3 & 0.3 \\
Coupling out of WG & 1.9 & 1.9 & 1.9 & 1.9 \\
QO losses & & & & 2.3 \\
Launcher losses & 0.5 & 1.0 & 1.0 & 1.8 \\
Losses from $H E_{11}$ & 15.3 & 11.1 & 9.7 & 9.6 \\
\hline
\end{tabular}

associated with the evacuated waveguide mitre bends are calculated with only seven bends rather than nine assuming the routing can be simplified, which will be discussed in section 3 . The WG31 and WG45 use phase-corrected mitre bends, which reduces the mode conversion losses. The phase-corrected mirrors are more expensive than the standard flat mirrors and are included in the costs given in table 2. The WG87-QO includes four mitre bends in the waveguide and nine mirrors in the QO sections.

\subsection{Compatibility with the JET installation}

A complete preliminary description of the WG45 [29] and WG87-QO [30] was compiled for comparison. The costs and transmission efficiency of the two systems were considered relatively equivalent. The only remaining factor was which system would integrate best in the JET installation. A description of the operating and safety requirements [31] of the ECRH transmission system in J1D and J1T was compiled by the JET operator and took into consideration the tritium containment in $\mathrm{J} 1 \mathrm{~T}$ and $\mathrm{J} 1 \mathrm{D}$, radiation shielding, vessel movements, torus access, E-M interference in J1T and J1D, and personnel safety. The WG45 design was stated as being fully consistent with the JET operator's requirements, including the solution for tritium leak prevention in J1D (see section 4.1). The release of tritium in J1T is also a severe issue since personnel access to the torus hall is required (no external vessel remote handling system). The operator preferred a transmission system that also provided tritium containment in $\mathrm{J} 1 \mathrm{~T}$, which is naturally achieved with the WG45 design but is difficult with the WG87-QO. The shielding/barrier around the QO section would block all personnel access along the ground floor in the south-east side of J1T, but access around the torus was a requirement of the operator. As a result of the operator's preference for an evacuated waveguide line, the design team recommended the WG45 for the JET-EP transmission line.

The preliminary description for the evacuated waveguide line [29] targeted the WG45 waveguide as the optimum diameter for the JET-EP ECRH project. This diameter offers a moderate power density in the waveguide and is fairly flexible to compensate for torus displacements. The report also described the use of the WG63 since this was the choice of the ITER ECRH waveguide. The JET-EP ECRH system aimed to be as ITER-relevant as possible, which implies the use of
WG63. Although WG45 is compatible with the ITER-ECRH system, with power densities equivalent to existing ECRH systems, the ITER waveguide diameter had been frozen at $63.5 \mathrm{~mm}$ prior to the design of the JET-EP ECRH transmisssion system. The WG63 waveguide elements could be designed for 2.0 MW operation and compatibility with both 113.3 and $170 \mathrm{GHz}$ frequencies to be used on JET-EP and ITER. The waveguide would first be used on JET-EP and then transferred to the ITER project, supplying all the needed waveguide elements for the European contribution to the ECRH system. A recycling of the waveguide elements from JET-EP to ITER would reduce costs to the European Community by half [32], from $90 \%$ of the WG87-QO price to $45 \%$, a savings of nearly 1.7 million euros.

\subsection{Transmission systems in future devices}

As noted above, the CVD discs for the window unit represent a significantly large portion of the costs $(\sim 25 \%)$ of the final WG87-QO proposal and as the technology improves in the growth of CVD discs, the window unit may decrease in cost, resulting in a more competitive price of the WG87-QO relative to the WG63 proposal. The total cost of the two proposals would be equivalent if there was a future price reduction of $\sim 65 \%$ in both the large- and small-diameter discs. If the technology improved and production increased to the extent that the two disc sizes were equivalent in price, the cost of the WG87-QO would be $\sim 6 \%$ less than the WG63. The range in costs from $+10 \%$ (today's cost) to $-6 \%$ (potential future price) is relatively small. One can conclude that the overall costs of the QO and evacuated waveguide systems are equivalent and that the cost is no longer a criterion for evaluating either system.

The installation of a transmission line on a future machine would be simplified compared with the JET-EP design. For example the routing can be optimized in advance, avoiding detours around exisiting structures as in the case of the JET-EP design, which would equally improve either transmission system. The optimum transmission system must take into consideration human and equipment safety, operational reliability, compactness, etc. A list of design criteria that were used by the JET-EP ECRH design team has been compiled in table 4. Criteria relevant only to the JET-EP machine have been excluded, keeping only criteria relevant to a future fusion machine equivalent to JET-EP or ITER. Both the QO and evacuated waveguide systems are compared for each criterion, and the system that best accomplishes the criterion is given a '+'; when the systems are equivalent, an '=' is used.

A brief justification of the comparison of selected criteria is provided herein. Tritium and stray radiation leakage: The WG63 system offers a natural containment for tritium leakage in case of CVD window failure at the torus or for stray radiation along the path of transmission from the gyrotron to the torus, and a QO system would require an additional containment device not included in the above costing. Space requirements: The evacuated waveguides are also more compact than the QO since higher power densities can be achieved in evacuated lines than at atmosphere. The power densities in QO lines can be increased by overlapping beams and transmitting the power in enclosures (such as in the W7-X ECRH project [25]) with controlled atmosphere; however, the cross section 
Table 4. List of criteria which can be used for evaluating a QO and evacuated WG system on a future machine. A ' + ' is given to the system that offers a better solution for each criterion (evaluation was performed by the JET-EP design team, which comprised members with experience in both QO and WG systems).

\begin{tabular}{lll}
\hline QO & Criteria & Evacuated WG \\
\hline$=$ & CVD window failure & $=$ \\
- & Tritium leakage & + \\
- & Space requirements & + \\
- & Stray radiation & + \\
$=$ & Operation reliability & $=$ \\
- & Neutron shielding & + \\
$=$ & Transmission efficiency and beam quality & $=$ \\
- & Integration of polarizer & + \\
+ & Vessel displacements & - \\
$=$ & Costs & $=$ \\
- & Alignment & + \\
- & Time and design effort & + \\
\hline
\end{tabular}

of such enclosures is large $(\sim 2.5 \mathrm{~m} \times \sim 2.5 \mathrm{~m}$, including space for human passage), whereas ten WG63 lines can pass in a $30 \mathrm{~cm} \times 75 \mathrm{~cm}$ cross section. Also, the expenses of such enclosures are non-negligible and hidden in building costs rather than in the transmission system. Integration of polarizer: Breakdown on the mirror surfaces (especially the grooved polarizers) are more likely to occur in atmospheric lines due to the accumulation of dust particles on the mirror surface. Neutron shielding: Smaller passages can be used with the compact WG63 than the WG87-QO, which simplifies the design and requirements of additional neutron shielding. Alignment: The WG63 is mechanically aligned using simple support structures in comparison with the high-power QO lines, which require a two-dimensional self-alinging system to insure continuous beam alignment $[26,27]$. Time and design effort: Since the WG63 elements are comercially available and the WG87-QO mirrors are designed typically for application on a specific machine, the time and design effort would be less for the WG63. Torus displacements: The design of the evacuated waveguide system must include either in-line bellows or long sections of waveguide to compensate for the tours displacement. The QO system does not require a mechanical connection with the torus, which simplifies the decoupling of the torus movement from the transmission system. However, a self-aligning system (as mentioned above) is required to maintain correct alignment into the torus.

The evacuated waveguide is equivalent or advantageous to the QO system in all but one of the design criteria. Therefore, the optimum system for transmitting the highpower microwaves from the gyrotron to the fusion device for both technical and financial reasons is the evacuated waveguide transmission line.

\section{Transmission line routing}

The six gyrotrons planned for the JET-EP ECRH project were to be located on the south side of the J1D building, with the MOU of each gyrotron connected to a waveguide line that transmits the microwave beam to the entry port of the launching antenna at the torus in J1T. Several possible routes from the gyrotrons to the torus were investigated, the optimum being the one that required the fewest modifications to existing structures and avoided all passageways (both personnel and overhead crane) while at the same time minimizing the number of mitre bends and the overall length of the lines. The routing chosen requires a total of nine mitre bends and an average length of $\sim 72 \mathrm{~m}$.

Each waveguide line leaves the MOU horizontally and travels to the east end of the gyrotron platform (see figure 1). A mitre bend (MB \#1) directs each waveguide downwards to a level $>2.5 \mathrm{~m}$ above the ground floor, and a second mitre bend (MB \#2) directs the lines towards the J1T building. After passing through the barrier between J1T and J1D, MB \#3 sends the beam upwards at an angle to a height $>7.2 \mathrm{~m}$ above the J1T floor (see figure 2). The waveguide lines follow a 'dogleg' (MB \#4-6) around the ventilation shaft in the south-east corner of J1T. This dogleg could be avoided by modifying the shaft and installing the line between the shaft and the wall. This would remove two mitre bends from the transmission line, reduce the overall cost and improve the transmission efficiency by $\sim 1.3 \%$. However, this option would modify existing structures; this was avoided in the preliminary design stage but would have been reconsidered if the project continued. After the ventilation shaft the line continues along the east wall until opposite the port in octant 1 (see figure 2); there, $\mathrm{MB}$ \#7, a power monitor mitre bend that monitors the forward and reflected power sends the waveguide towards the torus. A second dogleg (MB \#8 and 9) deviates the waveguide around the KN3 diagnostic and into the launching antenna's port.

Each line has a dc break at either end, providing electrical isolation of the line from the gyrotron and torus. The lines are evacuated via two pumping stations: at the MOU and via a pumpout tee near the barrier in J1T. There are two allmetal gate valves in each line that can isolate the different sections of the line based on the JET tritium barrier philosophy (see section 4.1). The first gate valve is positioned at the J1D-J1T barrier (inside J1T); this valve is normally closed during periods of non-operation to isolate the two vacuum regions of the line. The second gate valve is mounted on the launcher flange just after the CVD window (see section 4.5). This gate valve acts as an additional tritium barrier and permits the removal/re-installation of the CVD window unit without perturbing the torus pressure. The inter-vacuum space between the gate valve and CVD window can be pumped via a small flange on the gate valve. The double-disc CVD window unit is placed as close as possible to the launcher entrance (see section 4.1) for a more detailed description of the window unit. A small section of waveguide (WG63) is inserted into the launcher port, which reduces the number of internal mirrors from seven (WG87-QO) to four. A switching network is included in each line that deviates the beam either towards the tokamak or to a calorimetric load (see section 4.3). The transmission efficiency of the line is estimated to be $\sim 90.3 \%$ (see table 3 ). The losses include an estimated $3.8 \%$ of mode impurity from coupling into and out of the waveguide, $4.6 \%$ losses from a combination of Ohmic attenuation (from waveguide and mitre bends), $0.3 \%$ from CVD window reflections and $1.0 \%$ in the launcher (see table 3 ). The WG63 line is designed for operation at both 113 and $170 \mathrm{GHz}$. The higher-frequency operation has slightly lower losses in the mitre bends, which decreases the total losses to $8.8 \%$ of the fundamental $H E_{11}$ mode (transmission efficiency of $91.2 \%$ ). 


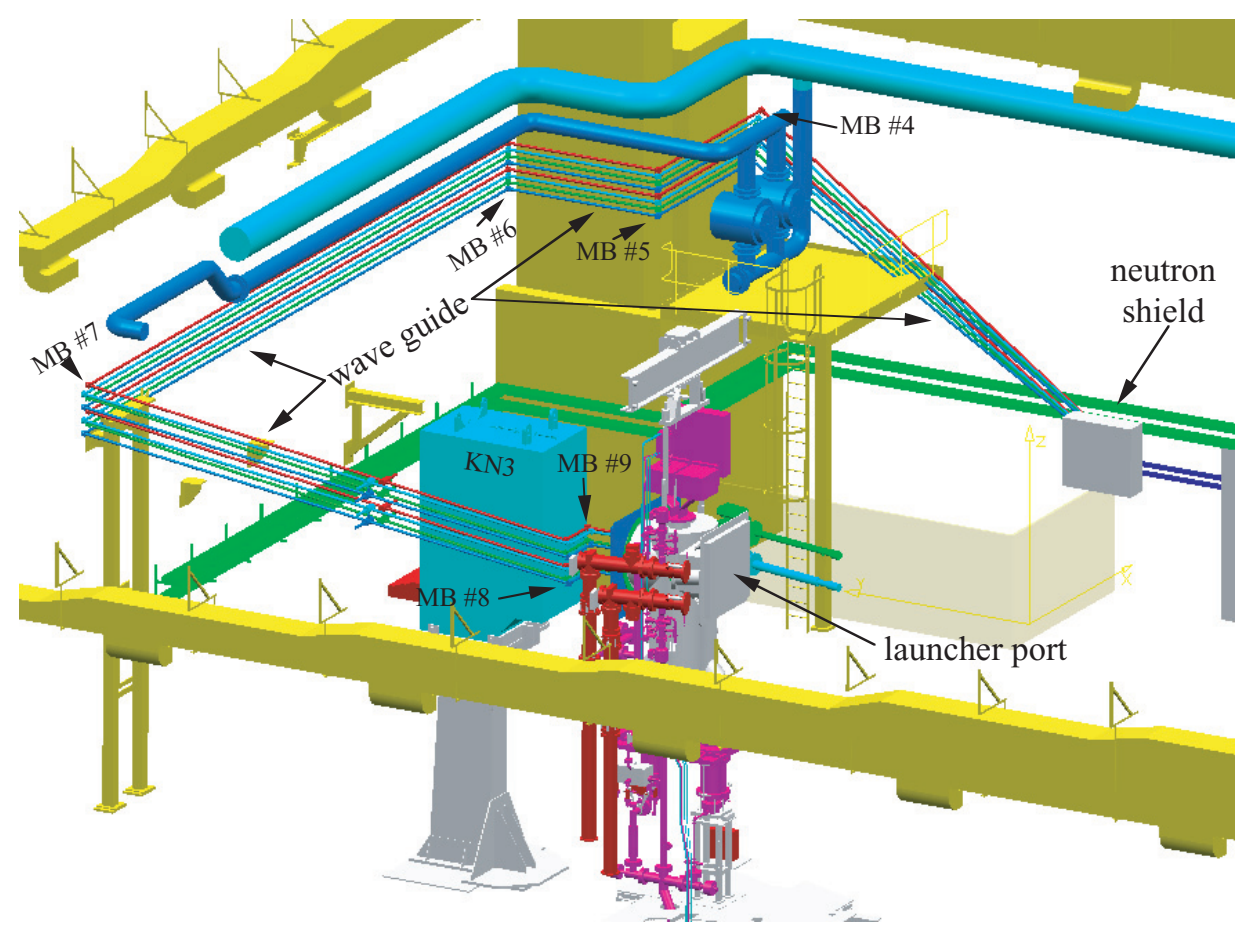

Figure 2. Waveguide run in J1T up to the entrance into the launcher port in octant 1 . The numbering of the mitre bends is shown, with MB \#7 a power monitor mitre bend. Note the JET tokamak is not shown in the figure.

\section{Specifics of the JET-EP transmission line}

Several criteria had to be met in the design of the waveguide line for the JET-EP project, which included the following: no tritium leakage from the torus via the transmission line, no neutron radiation into J1D from J1T via the waveguide passage through the wall, compensation of torus displacements due to disruptions and thermal cycles, minimization of obstructions from the transmission line, gyrotron conditioning and calibration capabilities, waveguide support locations, etc. A more detailed description of these topics can be found in the design review documentation [29] of the transmission line. Several of these topics are addressed in this chapter.

\subsection{Tritium and neutron barriers}

Risks associated with tritium leakage from the torus into either J1T or J1D via the transmission line was one of the greatest concerns of the JET operator. These risks were minimized by maintaining a tritium containment philosophy similar to that of the JET installation, with two barriers: the torus vessel and $\mathrm{J} 1 \mathrm{~T}$ enclosure. The first barrier at the wall of the vacuum vessel was maintained by a combination of an in-line all-metal gate valve, followed by an in-line double-disc CVD window. The ITER CVD window uses only a single disc, where the principle fault scenario arises from a ruptured disc caused by a 2 bar pressure wave of steam coming from a coolant leak in the torus. It is assumed an additional disc would fail shortly after the first, and so only a single disc is used. The CVD discs are designed for a 10 bar over-pressure, but a disc failure is hypothetically expected at 2 bar [33]. In ITER the CVD window is backed by an in-line gate valve (1 s closing speed) and an in-line pressure 'releaser'. The releaser vents the line to the tokamak hall when the pressure exceeds 1 bar. This limits the pressure in the waveguide and at the gyrotron window to 1 bar.

In JET the principle fault scenario is a rupture of the disc from microwave power and not from an internal torus explosion. Bursting discs on torus and inventory controls limit over-pressure in JET [31]. In the event of a failure of one disc due to RF power, the integrity of the second disc would still be maintained. Fibre optic arc detectors will monitor each disc for breakdown on the surface of the windows. In the event of a breakdown the respective gyrotron will be shut off on a fast timescale (order of a few microseconds).

The CVD window unit experiences three different vacuums, the torus vacuum on the side facing the torus, the waveguide vacuum on the side facing the gyrotron and the inter-space vacuum between the two discs. Each region is isolated, with the vacuum inter-space monitored continuously. A pressure change in the inter-space implies a rupture of the isolation between this volume and either the torus or waveguide vacuums. In this event, the security system assumes the leak comes from the torus and, therefore, the first CVD window tritium barrier has been compromised (this event is referred to as a CVD disc failure). In addition to stopping the pulse of the gyrotron, the gate valve at the torus would then close, blocking any potential tritium flux into the line. The other in-line gate valve at the J1T-J1D barrier and the gate valves on each pumping stations would close to minimize the potentially contaminated volume (see figure 3). The gate valves would not be fast-acting valves, and slower-acting valves $(\sim 0.5 \mathrm{~s})$ maintain a lower leak rate, which would not compromise the tritium barrier. The gate valve on the torus allows the removal of the CVD window housing unit for inspection/repair without perturbing the torus vacuum. Removal/installation of the CVD housing unit would require human intervention in J1T, and the torus side of the CVD window unit will have been exposed to tritium, requiring special handling. 


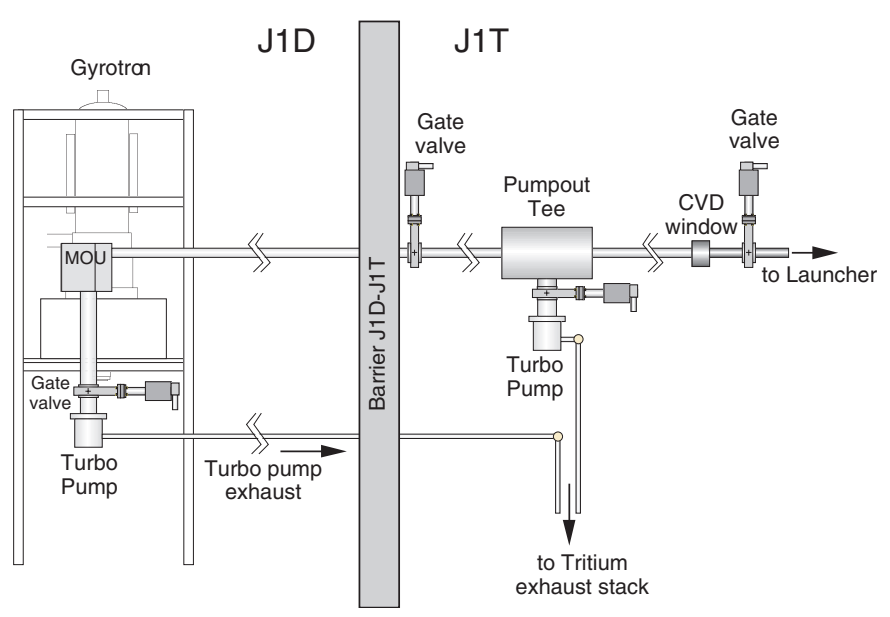

Figure 3. The two tritium barriers for the transmission line: first barrier (gate valve and CVD window) at the torus and second (gate valve and pump exhaust routing) at the J1T-J1D wall.

The second tritium barrier at JET is located at the wall between J1T and J1D. The waveguide passing through this wall could be a potential passageway for tritium from $\mathrm{J} 1 \mathrm{~T}$ into J1D. In the event of a fast rupture of both discs in the CVD window, some tritium would pass into the waveguide line before all of the gate valves closed. Most of the tritium would be pumped via the pumpout tee located near the J1T-J1D interface; however, some particles could continue to flow upstream in the direction of the MOU pumping station. These particles would be blocked by an all-metal gate valve located on the inside wall between J1T and J1D. The CVD disc failure would also trigger closing of the gate valves on all the pumping stations, which would confine the tritium to the waveguide volume. The exhaust of all pumping stations will be permanently channelled back to the exhaust stack in $\mathrm{J} 1 \mathrm{~T}$ in the event the gate valves fail to close. This provides a third barrier and a final protection to insure no tritium leakage into J1D, thus limiting the contamination to the waveguide and MOU volumes.

In the event of a tritium leakage in J1T (leakage not related to the ECRH system), the waveguide vacuum joints will be all tested to insure He leak rates of $<10^{-8}$ mbar $* 1 \mathrm{~s}^{-1}$. The passage of the waveguide through the barrier between J1D-J1T is also susceptible to leakage of tritium into J1D. An end cap with an O-ring seal around the waveguide will be placed on the $\mathrm{J} 1 \mathrm{~T}$ side of the barrier. Although the end cap is not required to be airtight since J1T is kept at a lower pressure than J1D, the O-ring provides an added security of avoiding particles flowing into J1D from J1T.

During D-T campaigns at JET, the barrier between J1T and J1D also acts as a neutron shield. Holes of about $100 \mathrm{~mm}$ in diameter will be drilled through the wall to allow passage of the waveguides. These holes reduce the shielding ability of the J1D-J1T barrier. Initial calculations for estimating the neutron flux on the J1D side of the barrier were performed with holes of $200 \mathrm{~mm}$ for the WG87-QO design. Placing a concrete shield of $50 \mathrm{~cm}$ thickness after the opening (see figure 2) and backfilling the hole with polyurethane beads provided sufficient shielding in agreement with the health and safety standards of UKAEA ( $<1 \mathrm{mSvert}$ per year in the worst location). The neutron flux rates for the WG63 design will be significantly lower than those calculated for the WG87-QO design. WG63

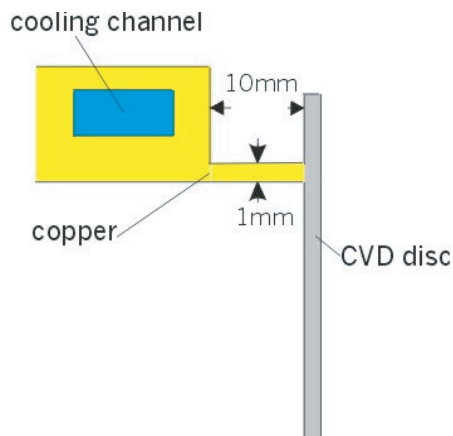

Figure 4. Brazing collar with cooling channel [35] to be connected to the CVD discs (see also figure 5), detail A. The brazing technology to be used is from TED, France.

requires a $<100 \mathrm{~mm}$ hole, plus the penetration in $\mathrm{J} 1 \mathrm{~T}$ has been moved several metres off-axis from the north-south axis of the machine, and the neutron flux rates for the WG63 were not calculated due to the discontinuation of the JET-EP ECRH project.

\subsection{CVD window}

Recently there has been a lot of experience gained with CVD windows on high-power microwave transmission lines [34]. On JET-EP the CVD window acts as the principal tritium barrier between the plasma and the waveguide line, as described earlier. The CVD window unit has been designed by the FZK group, and a full description of the CVD window unit, including the reflectivity calculations, is provided in [35]. The preliminary design uses a $74 \mathrm{~mm}$ diameter disc with a copper cooling channel brazed directly on one side (see figure 4). This is achieved using a new brazing technique developed by Thales electron devices (TED), France and improves the heat conduction path from the window to the coolant. Brazing only one side of the disc allows the window unit to be designed with a very narrow inter-space region that is optimum for low reflectivity and large bandwidth. The preliminary design of the housing unit is shown in figure 5, including cooling feeds, arc detectors and ion getter pump feed-through. The thickness of the disc are $d_{\mathrm{CVD}}=1.111 \pm 0.010 \mathrm{~mm}$ and the gap is $3.2-3.4 \mathrm{~mm}$. In order to maintain the low reflectivity 


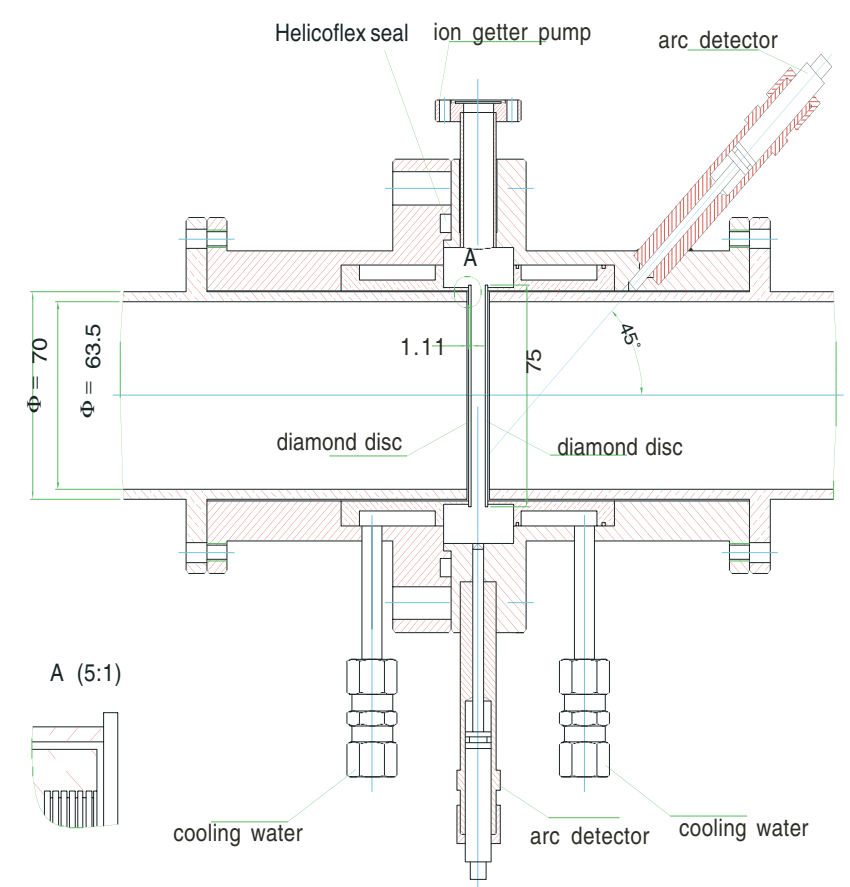

Figure 5. CVD window housing unit [35] to be used on the JET-EP transmission line. The brazing collar shown in figure 4 allows the two CVD discs to be placed close together for a larger bandwidth in transmission. Two arc detectors and pumping access to the inter-CVD disc space is included in the CVD housing structure.

of the two-disc assembly, the variation in thickness between the two discs should not exceed $\pm 0.005 \mathrm{~mm}$. The reflectivity for such a configuration is $-25 \mathrm{~dB}$ for $113.3 \mathrm{GHz}$ and $-22 \mathrm{~dB}$ for $170 \mathrm{GHz}$. For ITER application the gap distance would be decreased between 3.0 to $3.2 \mathrm{~mm}$, which corresponds to the optimum for $170 \mathrm{GHz}$. The overall bandwidth of the window unit is $\sim 2 \mathrm{GHz}$ including variations in the gap size due to thermal expansion of the brazed copper channel. At least one manufacturer has stated that the added restricition of providing two discs with a variation of thickness $0.005 \mathrm{~mm}$ can be realized without increasing the cost of the CVD discs.

An alternative concept to the CVD window brazing shown in figure 4 is the use of a Helicoflex ${ }^{\circledR}$ seal between the waveguide and CVD disc. Helicoflex ${ }^{\circledR}$ seals have already been installed in the $\sim 1.0 \mathrm{MW}$ WG31 systems at LHD as mentioned earlier. The thermal conductance of the WG63 is approximately $35 \mathrm{~W}^{\circ} \mathrm{C}^{-1}$ (nearly four times greater than the copper brazed cooling channel) [14]. With the improved themal conductivity of the Helicoflex ${ }^{\circledR}$ seal, cooling of the window can be achieved via the waveguide (which has auxillary cooling) and avoids direct cooling of the CVD disc and copper brazing. Assuming $1 \mathrm{~kW}$ of absorbed power in the disc, the edge temperature would rise less than $30^{\circ} \mathrm{C}$ with the Helicoflex ${ }^{\circledR}$ seals, in contrast to a $124^{\circ} \mathrm{C}$ rise with the water-cooled brazed copper tube. The CVD window unit with Helicoflex ${ }^{\circledR}$ seals also offers other advantages such as easier replacement of damaged discs, a less expensive housing unit, avoiding potential contamination of the diamond due to brazing, and availability of Helicoflex ${ }^{\circledR}$ seals for bakeout temperatures. The Helicoflex ${ }^{\circledR}$ seals have He leak rates equivalent to current brazing techniques and are currently in use at JET-EP under conditions of high neutron flux in scenarios similar to ITER's.

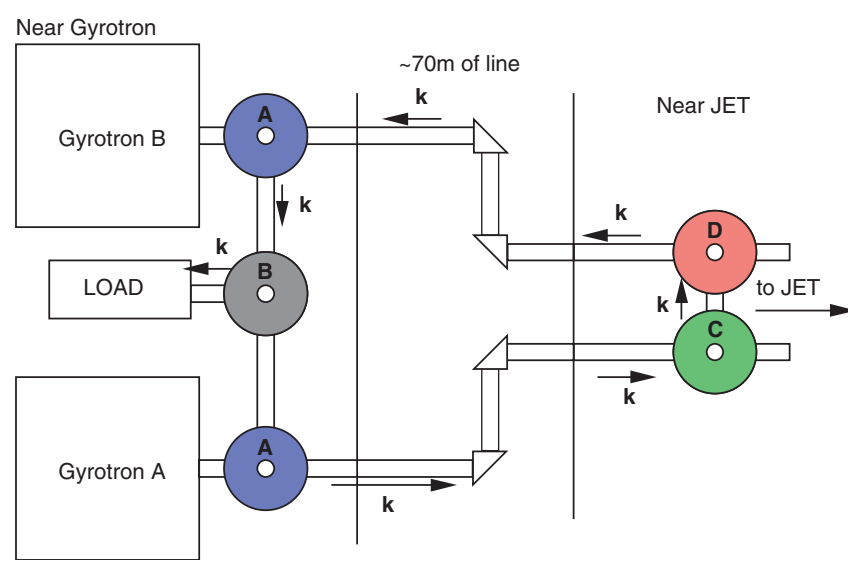

Figure 6. Schematic of the switching system for conditioning of the gyrotrons and calibration of the line in situ. One load is shared between two neighbouring gyrotrons. The dual switching network permits conditioning and calibration of both the gyrotron and transmission line remotely. The switch type A has three positions, while $\mathrm{B}, \mathrm{C}$ and $\mathrm{D}$ have two positions.

\subsection{Calibration and conditioning}

The gyrotrons will need to be operated either into the tokamak or a calorimetric load with switching between the two targets made from a remote operation. For example, at the beginning of an operating day the gyrotrons will need to be fired for short pulses (from 1 to $\sim 100 \mathrm{~ms}$ ) to insure the correct operating beam current. This operation requires directing the beam into a load rather than the torus (stray microwave power in the torus would cause damage to some diagnostics even at short pulses). Also, gyrotron conditioning will be needed after long periods of down time, which requires the use of a long pulse load. To achieve both these requirements, a high-power microwave switch is positioned near each gyrotron, directing the beam either to JET or to a calorimetric load shared between two gyrotrons. When a given gyrotron needs conditioning, a single spare long-pulse load could be installed (long-pulsed loads cost a factor of 2.5 more than short-pulsed loads).

An additional switching system is added near the torus, which directs the beam either to the torus or to the load near the gyrotron via a return path in a neighbouring line. The switching scheme followed the system planned for the W7-X ECRH QO transmission line [25] and permits conditioning and calibration of nearly the entire line to full power (see figure 6). The switch near the gyrotron (switch 'A' of figure 6 has three positions, directing the beam either forwards to the torus, towards the load with beam coming from the gyrotron or towards the load with the beam coming from the neighbouring gyrotron via the switching network near the torus. The additional switching unit near the torus also allows calibrating the delivered power to the torus without personnel access to the J1T zone.

The delivered power to the launcher will be monitored actively using the grating mirror in the MOU (described in section 1). The signal at the MOU can be cross-calibrated from the calorimetric power measurement using the above switching system. A power monitor mitre bend (PMMB) will be added in the transmission line that can be used for near real time measurement of the polarization [36]. 


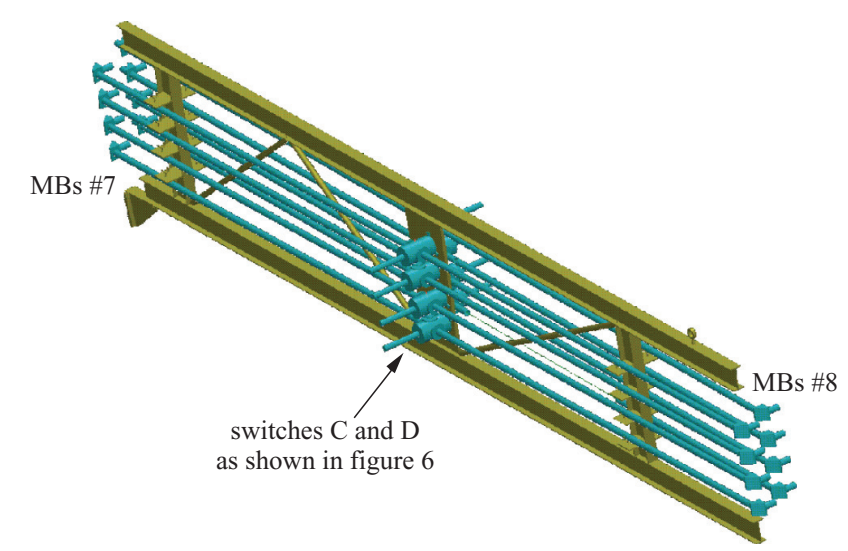

Figure 7. A trestle bridge structure is to be used to support the waveguide from the east wall of $\mathrm{J} 1 \mathrm{~T}$ to the entrance into the launcher port. The structure is designed to allow the quick removal of the eighth waveguide leg for installation of the RHU for access to the torus.

\subsection{Insertion of remote handling unit}

Remote handling and manned access to the torus is achieved through octant 1 , the same port used by the ECRH launching antenna. The waveguide from the east wall up to the torus entry and the launcher must be removed in order to install structures associated with the remote handling unit (RHU). The procedure in dismounting/mounting the transmission line for installation of the RHU should require less than one week. The support structures for this waveguide section are designed to aid in quick removal and re-mounting of the waveguide elements. The whole assembly, for all six or eight lines, from the PMMB (MB \#7) up to the launcher, will be removed in a two sections. The first section is mounted on a 'trestle bridge' structure and includes all elements from the PMMB to the MB \#8 (see figure 7). The elements are fixed on the trestle, which is supported by two brackets mounted on the east wall and by a hook mounted on the torus structure and used for supporting the RHU. The whole trestle structure can be lifted by the overhead crane and removed from the $\mathrm{J} 1 \mathrm{~T}$ zone.

The second waveguide section, which is removed for installation of the RHU, includes the waveguide elements after MB \#8: the CVD window housing unit, the MB \#9 and the torus gate valve. These items are normally held in place by a support frame bolted to the launcher flange and move with the torus/launcher during disruptions or thermal cycles. The support frame also protects the CVD window from stresses associated with torus displacement (see section 4.5). The removal of this section is achieved by unbolting the gate valves from the waveguide feed-throughs welded on the launcher flange, and then disconnecting the frame from the launcher flange and removing the whole section with the overhead crane.

The installation of the two sections after the removal of the RHU is made in the opposite order. The waveguide support structures on both the trestle bridge and the support frame are designed to include some flexibility for re-aligning the waveguides when they are installed. The overall removal or installation is estimated to take only a few days and requires human intervention in J1T.

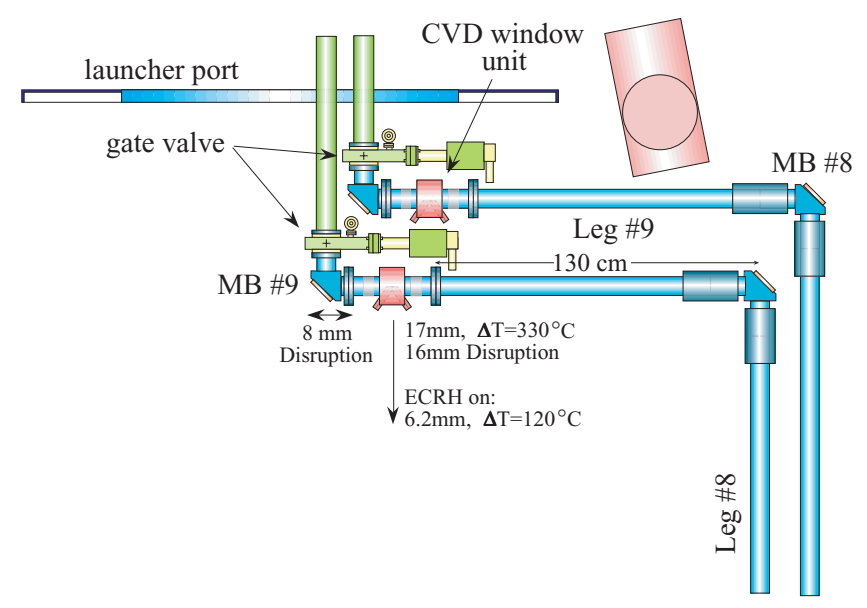

Figure 8. The launcher port will move radially up to $17 \mathrm{~mm}$ during torus baking. Also, the port may move $16 \mathrm{~mm}$ radially and $8 \mathrm{~mm}$ toroidally during disruptions. Waveguide leg \#8 will bend to compensate for toroidal movement and leg \#9 will bend to compensate for radial movement. Both sections are long enough to ensure the induced stresses are below the yield strength of aluminium.

\subsection{Line-launcher interface}

The interface between the transmission line and the launching antenna (launcher) was complicated by torus displacement during disruptions and thermal cycles. The launcher, mounted in the port of octant 1 , is to move with the torus, while the transmission line leading up to the launcher is fixed in place. The outer flange of the launcher can move up to $8 \mathrm{~mm}$ toroidally and $16 \mathrm{~mm}$ radially during a disruption and $17 \mathrm{~mm}$ radially due to thermal expansion when heating the torus (see figure 8). The waveguides are to be aligned (unstressed) when the torus is hot to reduce the induced stresses; thus the maximum radial displacements will be $\pm 16 \mathrm{~mm}$ (disruption) or $-17 \mathrm{~mm}$ (cooled torus) but never addition of the two displacements simultaneously. Normally, the waveguide can easily accomodate such displacements with the addition of in-line bellows at the entrance to the launcher and long (a few metres) straight sections that can easily bend (elastically). The installation of the waveguide line at JET-EP was complicated due to the presence of the KN3 diagnostic just behind the launcher entrance, which limited the available space.

The radial displacement of the torus is compensated for by bending waveguide leg \#9. The $90^{\circ}$ angle of the mitre bends before the leg and the CVD window unit after the leg are assumed to be rigid and it was assumed that the waveguide will form an 's' bend as the torus expands radially. A length of $1.2 \mathrm{~m}$ was used in a preliminary calculation of the induced stresses in the section of waveguide (actual length between mitre bend and CVD window support is $1.35 \mathrm{~m}$ ). The $17 \mathrm{~mm}$ displacement at the torus results in an elastic deformation of the waveguide, with the induced stress related to less than $80 \%$ of the yield strength. The induced stress could be further reduced by increasing the length of waveguide leg \#9 and/or by adding in waveguide leg \#8 an in-line bellows that would compress as the torus expanded radially. The $8 \mathrm{~mm}$ toroidal expansion will be accommodated by the waveguide preceding MB \#8, which will be $>1.5 \mathrm{~m}$ in length, before the next support. The 8th mitre bend positioned between waveguide legs \#8 and 9 will be free floating. 


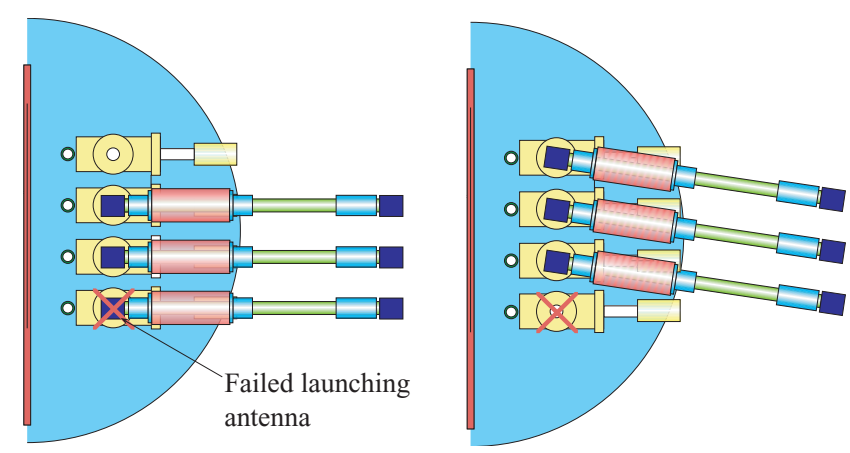

Figure 9. Waveguide leg \#9 can be modified to reconnect the gyrotron to a new launcher in case a given launcher fails. The worst case scenario is shown: launcher \#2 fails, which requires shifting lines \#2, 4 and 6 to launchers \#4, 6 and 8 .

The waveguides will be relatively straight $\left(>0.2^{\circ}\right)$ when there is power transmitted to the launcher since the lines are aligned and mounted when the torus is hot. There will be no power transmitted when the torus is cool or during a disruption (the gyrotrons will be stopped before the disruption event). The operating temperature of the JET torus varies depending upon the operating series $\left(\delta T=120^{\circ} \mathrm{C}\right)$, and this variation corresponds to a $6.2 \mathrm{~mm}$ (or $\pm 3.1 \mathrm{~mm}$ ) change in radial position at the launcher. Approximately $0.08 \%$ of the transmitted power will be converted to lower-order modes when the torus is operated either at $200^{\circ} \mathrm{C}$ or $320^{\circ} \mathrm{C}$ (waveguide is 'straight' at $260^{\circ} \mathrm{C}$ ).

Of the eight antennae in the JET-EP launcher, the upper two are reserverd as spares that could be used if one of the other antennae failed or if a $170 \mathrm{GHz}$ gyrotron was procured. In the event of a launcher failure, the waveguide lines leading up to the torus can be modified to connect a given gyrotron to a spare antenna. Figure 9 illustrates how such an operation would occur for a malfunction of the bottom launcher (the most complicated scenario); in this case, launcher \#2 fails. The waveguide lines \#4 and 6 also have to be re-connected as shown since the waveguides leading to launchers \#2, 4, 6 are all in the same vertical plane. The three gate valves before the torus would be closed and the line(s) tilted as shown in the right-hand side of the figure. Pumping the region between the gate valve and the CVD window is made via a pumping port on the gate valve. This manipulation would require human intervention into $\mathrm{J} 1 \mathrm{~T}$ and approximately one day for modifying the mounting and alignment of the waveguides.

\subsection{Waveguide interlocks for gyrotron operation}

All microwave components have either no or very low microwave leakage (the dc breaks are the only components with some leakage, which are below safety requirements, $5 \mathrm{~mW} \mathrm{~cm}^{-2}$ at a distance of $3 \mathrm{~cm}$ ). There is also little risk from electrical shocks. The coupling system between waveguide pieces are all metal and are designed to insure high electrical conductivity from piece to piece. The whole transmission line is isolated electrically from the gyrotrons and the torus by dc breaks on both ends of each line, with all lines connected to the building ground.

Since there is relatively no risk to personnel safety, the transmission line's interlock system is mainly designed for protection of the waveguide elements and the gyrotrons from damage arising from a breakdown or reflected power. Provided the RF pulse is stopped quickly $(\sim 10 \mu \mathrm{s})$, a breakdown in evacuated waveguide lines does not damage the waveguide elements (mirrors and CVD window). Two arc detectors are installed on each mitre bend mirror for monitoring the occurrence of RF breakdowns in both the forward and reflected directions. In addition to RF breakdowns the transmission line or reflections from the plasma back into the waveguide may return some power to the gyrotron, which can result in breakdown within the tube. This can be avoided by monitoring the reflected power via the PMMB. In the event of either a breakdown in the waveguide or a high level of reflected power, a fast trip will be sent to stop the power supplies.

The forward power signal will also be monitored to insure the gyrotron is in the correct operating mode. In the event of a mode switch there is a sharp decrease in the output power of the gyrotron and is potentially damaging to the gyrotron. The change in mode will increase the thermal load on the collector and generate excessive stray microwave radiation, which is absorbed in either the gyrotron or MOU. The grating mirror power monitor in the MOU (see description of MOU in section 1) will detect such decreases in the forward power and generate a signal to stop the power supplies. Such steps in power can also be generated by a change in the gyrotron's operating parameters, for example cathode or anode voltage, beam current, cavity or cathode magnetic field, etc. Fast deviations of the measured power relative to the calculated expected output power based on the gyrotron operating parameters will be considered as mode jumps and will set of stopping the power supplies.

The vacuum pressure in each section of the transmission line will be actively monitored, and pressures above $10^{-5} \mathrm{mbar}$ will block operation. The vacuum interlocks will be used to block opening of gate valves if one side is at atmospheric pressure while the other is under vacuum.

\subsection{Waveguide supports}

Both the mitre bend and the waveguide supports to be used at JET-EP are taken from a modified version of the supports used on the WG63 TCV-ECRH transmission line [23]. The supports are simple in design and relatively inexpensive to machine. Most of the mitre bends will be held in place in a block assembly where possible (see figure 10(a)). The whole assembly is supported from a structure that can be adjusted vertically and horizontally for alignment. The waveguides will be supported by a set of cradles positioned periodically along the length of the waveguide (see figure $10(b)$ ). The cradles are each mounted on a rail allowing horizontal alignment. Each rail is fixed to a bar that aligns the whole assembly vertically. Alignment and mounting of the transmission lines will follow the same procedures as was followed in the TCV system. A precision of $\sim 0.5 \mathrm{~mm}$ between supports can be achieved using a simple laser placed co-axially with the output of a mitre bend section. The laser beam provides a reference for positioning the next mitre bend and intervening waveguide supports along the path of the transmission line.

The spacing of the supports will be chosen by minimizing the calculated power converted to other modes due to 
(a)

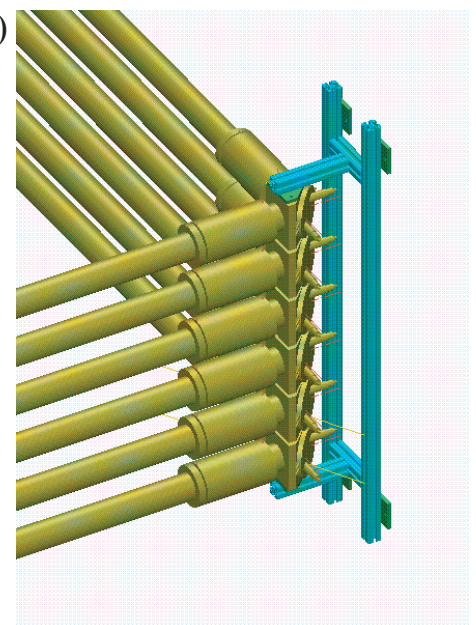

(b)

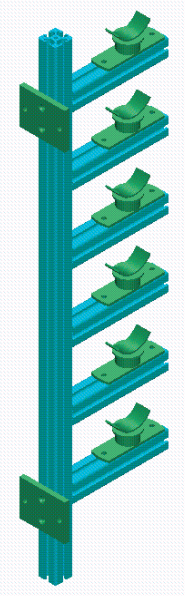

Figure 10. The support structures for $(a)$ mitre bends and (b) waveguides are designed after the supports used on the TCV ECRH transmission line/citegoodman01. Both systems allow horizontal and vertical alignment to less than $\pm 1 \mathrm{~mm}$.

misalignments and waveguide sagging. Small distances between supports create a high level of mode converted power from small misalignments between the supports, while large distances between supports create a high level of mode converted power from sagging of the waveguide due to gravity. A typical line of $72 \mathrm{~m}$ length was investigated to determine the optimum range for the distances between supports. As a first step the total power converted from waveguide sagging to all higher-order modes at the end of the line was calculated for constant spacing between supports over the entire length of the line. For the same spacing the power converted due to a $1 \mathrm{~mm}$ shift between two supports was calculated and then multiplied by the number of supports used in the line (see figure 11). The addition of these two losses yielded a minimum converted power for support spacings between 4 and $6 \mathrm{~m}$. Support spacings of 3.5 and $7 \mathrm{~m}$ were to be avoided, these lengths corresponding to a beat wavelength between the fundamental and a higher-order mode. The estimated power losses for the misalignment and waveguide sagging provides an upper bound on the power converted to other modes.

The next step, had the project continued, would have been to determine the possible support locations available at the JET site and optimize the choice based on the minimum amount of converted power to other modes. Also, the misalignment error would have been randomly varied between +1 and $-1 \mathrm{~mm}$ for all the possible support configurations. The support positions with the lowest average power converted to other modes would have been chosen.

\subsection{Cooling system}

All elements of the transmission line (aside from the PMMB) are designed for both operating frequencies (113.3 and $170 \mathrm{GHz}$ ) and power levels of up to $2.0 \mathrm{MW} \mathrm{CW}$ operation. Many of the elements absorb small amounts of power and therefore require either active or passive cooling systems (active: mitre bend, CVD window, gate valve, switch, load). All but the CVD window and torus gate valve will use de-ionized cooling water coming from the gyrotron cooling circuits. Items

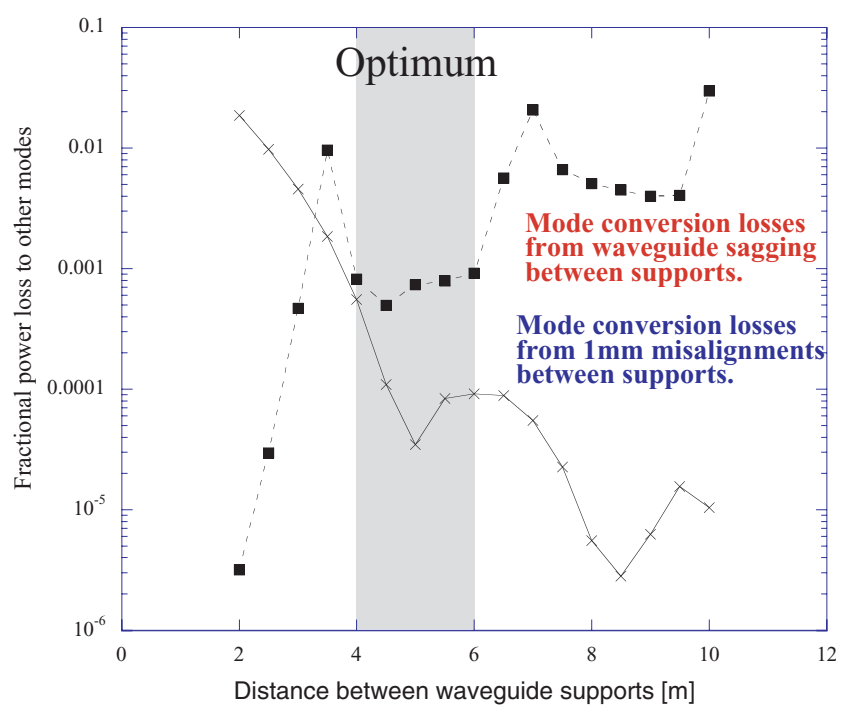

Figure 11. Fractional power converted to higher-order modes from sagging and misalignment of the waveguide versus the distances between supports. The sum of the two curves has a minimum for support spacings between 4 and $6 \mathrm{~m}$.

exposed to the torus vacuum have special cooling circuits that can be quickly drained if a water leak is detected in the torus. All other elements, including the waveguide lines, will use passive cooling systems. Approximately $38 \mathrm{~kW}$ per line will be absorbed in the waveguide due to Ohmic attenuation and the absorption of all higher-order modes converted in the mitre bends. Assuming a heat transfer of the outer surface of the waveguide of $5 \mathrm{~W}\left(\mathrm{~m}^{-2}{ }^{\circ} \mathrm{C}^{-1}\right)$ and a duty cycle of $1 \%$, there will be a $\sim 3^{\circ} \mathrm{C}$ rise in temperature during long periods of operation not requiring active cooling [28]. With a thermal expansion of $23 \times 10^{-6} \mathrm{~m}^{\circ} \mathrm{C}^{-1}$, the longest waveguide run $(\sim 19.5 \mathrm{~m})$ would expand $1.8 \mathrm{~mm}$, which will be compensated by in-line waveguide bellows. The bellows are inserted in long, straight sections of waveguide runs to compensate for thermal expansion due to changes in the room temperature, which can vary up to $20^{\circ} \mathrm{C}$ during the year.

For ITER, with $2 \mathrm{MW} \mathrm{CW}$ operation, the WG63 Ohmic attenuation and absorption of higher-order modes will result in a temperature rise of $\sim 360^{\circ} \mathrm{C}$ with no active cooling on the waveguide pieces. Manufacture of the waveguide pieces will therefore include external cooling channels for ITER but these will not be utilized when installed on JET-EP.

\section{Conclusion}

Despite the demise of the JET-EP ECRH project, the design study of the transmission line system has been a useful exercise that may prove beneficial in the design and construction of future devices with high-power microwave heating systems. The tritium containment philosophy used in this study offers a reliable system that could be used as the basis for the ITER design. Likewise, the novel switching system, which allows conditioning and calibration of the entire system without human intervention, can easily be applied to the ITER-ECRH system. The switching system also shares one load between two gyrotrons, which reduces the costs of the line by $\sim 10 \%$. Several steps were taken in the design of the WG63 to reduce 
the cost while maintaining the same performance, including sharing of the load between two gyrotrons and simplified support structures. These steps can easily be used for future installations.

Preliminary comparisons of the different transmission line systems (QO, atmospheric and evacuated waveguide lines) lead to the conclusion that the cost differences between the various transmission systems were small or favourable towards the evacuated waveguide lines (based on August, 2002 prices). In particular, the traditional view that QO lines are much less expensive than evacuated waveguide lines has been shown to be false, especially for high-power microwave systems that require CVD diamond windows. The final transmission system chosen for JET-EP was the $63.5 \mathrm{~mm}$ evacuated corrugated $H E_{11}$ waveguide, which offers compactness, high transmission efficiency and security from tritium leakage and microwave radiation in $\mathrm{J} 1 \mathrm{D}$ and $\mathrm{J} 1 \mathrm{~T}$ with out additional costs compared with a hybrid atmospheric waveguide-QO transmission line. In addition, the waveguide elements can be re-used at the ITER-ECRH project, supplying all the waveguide elements for the European Community's contribution. Sharing of the waveguide represents a $50 \%$ reduction in procurement costs and a savings of 1.7 million euros to the EU fusion community. A comparison of the transmission systems for future machine applications favoured the evacuated waveguide over the QO system (see table 4).

\section{Acknowledgments}

The author would like to acknowledge the technical support from the many people of UKAEA-Fusion who were very helpful in answering the numerous questions asked in an attempt to make the transmission line compatible with the JET site. The author would also like to thank Jo Lister for his useful comments on this paper.

This work was performed under the European Fusion Development Agreement and was supported in part by the Swiss National Science Foundation and in part by EURATOM.

\section{References}

[1] Verhoeven A.G.A. et al 2003 The $113 \mathrm{GHz}$ ECRH system for JET Proc. 12th Joint Workshop on ECE and ECRH (Aix-en-Provence, 13-16 May 2002) (Singapore: World Scientific) pp 511-16

[2] Pamela J. 2001 JET under EFDA: organisation, recent results and prospects Fusion Eng. Des. 56-57 19-28

[3] Henderson M.A. et al 2003 Design of the evacuated waveguide transmission lines for JET-EP Proc. 12th Joint Workshop on ECE and ECRH (Aix-en-Provence, 13-16 May 2002) (Singapore: World Scientific) pp 529-34

[4] Elzendoorn B. et al 2002 Design of the ECRH launcher on JET Proc. 22nd Symp. on Fusion Technology (Helsinki) Fusion Eng. Des. submitted

[5] Doane J. 1992 Grating Polarizers in Waveguide Miter Bends Int. J. Infrared Millimeter Waves 13 1727-43

[6] Shi J. and Kasparek W. A grating coupler for in situ alignment of a Gaussian beam-principle, design and low-power test IEEE AP submitted

[7] Henderson M. et al General description of the evacuated wave-guide transmission line for the JET-EP ECRH Project LRP 735/02
[8] Fernandez A. et al 2001 Transmission line design options and costing JET-EP ECRH Desgin Review Meeting (Culham, 12-13 March 2001) available at http://www.rijnh.nl/n7/docframe.htm

[9] Verhoeven A.G.A et al 2001 The ECRH system for JET-EP Proc. Display and Vacuum Electronics (Garmisch-Partenkirchen, 2-3 May 2001) p 345

[10] Verhoeven A.G.A et al 2001 The ECRH system for JET Proc 25th IR\&MMW Conf. (Toulouse, 12-15 September 2000)

[11] Fernandez A. et al 2001 Conceptual design of quasi-optical transmission lines for JET-EP Proc. 25th IR\&MMW Conf. (Toulouse, 12-15 September 2000)

[12] Hoekzema F. 2001 Transmission line and Launcher design Meeting of the CC-ECW (Geneva, 3-4 July 2001)

[13] Fernandez A. 2001 QO transmission line Meeting of the CC-ECW (Geneva, 3-4 July 2001) available at http://www.rijnh.nl/n7/docframe.htm

[14] Doane J. 2003 Waveguide diamond vacuum windows with Helicoflex ${ }^{\circledR}$ seals Proc. 12th Joint Workshop on ECE and ECRH (Aix-en-Provence, 13-16 May 2002) (Singapore: World Scientific) pp 456-60

[15] Hasegawa M. et al 2001 Current startup with an ECH system on TRIAM-1M 43rd Meeting of the DPP-APS (Long Beach)

[16] Callis R.W. et al $19983 \mathrm{MW}, 110 \mathrm{GHz}$ ECH system for the DIII-D tokamak Proc. 20th Symp. on Fusion Technology (Marseille) vol 1, pp 315-8

[17] Ikeda Y. et al 2001 Initial results of electron cyclotron range of frequency (ECRF) operation and experiments on JT-60U Fusion Eng. Des. $\mathbf{5 3} 351$

[18] Shimozuma T. et al $2001 \mathrm{ECH}$ system and its application to long pulse discharge in large helical device Fusion Eng. Des. 53 525-36

[19] Ikeda Y. et al 2003 Recent progress in the $110 \mathrm{GHz}$ ECRF system on JT-60U tokamak Proc. 12th Joint Workshop on ECE and ECRH (Aix-en-Provence, 13-16 May 2002) (Singapore: World Scientific) pp 475-80

[20] Lohr J. et al 2003 High power long pulse performance of the DIII-D gyrotron installation Proc. 12th Joint Workshop on ECE and ECRH (Aix-en-Provence, 13-16 May 2002) (Singapore: World Scientific) pp 283-9

[21] Shimozuma T. et al 2003 ECRH experiments in an extended power regime on the large helical device Proc. 12th Joint Workshop on ECE and ECRH (Aix-en-Provence, 13-16 May 2002) (Singapore: World Scientific) pp 359-64

[22] Darbos C. et al 2001 The 118 GHz ECRH experiment on Tore Supra Fusion Eng. Des. 56-57 605-9

[23] Goodman T.P. et al 1996 Proc. 19th Symp. on Fusion Technology (Lisbon) vol 1, p 565-8

[24] Koppenburg K. et al 2003 Experimental results of the $140 \mathrm{GHz}, 1 \mathrm{MW}$ long-pulse gyrotron for W7-X Proc. 12th Joint Workshop on ECE and ECRH (Aix-en-Provence, 13-16 May 2002) (Singapore: World Scientific) pp 433-42

[25] Kasparek W. et al 2001 Frequenz 9-10 55 263-9

[26] Idei H. et al 2003 Developement of quasi-optical components for electron cyclotron heating based on phase measurements Proc. 12th Joint Workshop on ECE and ECRH (Aix-en-Provence, 13-16 May 2002) (Singapore: World Scientific) pp 517-22

[27] Kasparek W. et al 2003 Beam waveguide reflector with integrated direction-finding antenna for in situ alignment Intl. J. Infrared Millimeter Waves 24 451-72

[28] Doane J.L. GA Some design considerations for high-power corrugated waveguide transmission lines General Atomics Internal Report submitted

[29] Henderson M. et al LRP 719/02: CRPP's evacuated waveguide proposal for JET-EP ECRH transmision line and available at http://www.rijnh.nl/n7/docframe.htm

[30] Hoekzema J.A. et al JET-ECH-TLR-T-002: preliminary design report for QO transmission line and available at http://www.rijnh.nl/n7/docframe.htm 
[31] Kaye A.S. JET EP-ECH-GEN-T-002: operator requirements for the ECRH transmission lines and available at http://www.rijnh.nl/n7/docframe.htm

[32] Henderson M.A. 2001 Meeting of the CC-ECW (Geneva, 20-21 November 2001) available at http://www.rijnh.nl/n7/docframe.htm

[33] ITER Design Description Document G 52 DDD 5 01-05-29 W 0.1
[34] Thumm M. 2001 Diamond Relat. Mater. 10 1692-9

[35] Piosczyk B. JET-ECH-TLR-WIN-R-001: 2001 FZK final order report and available at http://www.rijnh.nl/n7/docframe.htm

[36] Ikezi H. et al 1999 Rev. Sci. Instrum. 70 1994-8

[37] Doane J.L. and Moeller C.P. 1994 Int. J. Electron. 77 489-509 


\section{Summary of Comments on nf169409}

Page: 13

Sequence number: 1

Author:

Date: 07-Oct-03 3:32:19 PM

Type: Highlight

1.7 million

Sequence number: 2

Author:

Date: 07-Oct-03 3:32:32 PM

Type: Note

$\mathrm{Au}$ : Pls check change if ok

Sequence number: 3

Author:

Date: 07-Oct-03 3:32:55 PM

Type: Highlight

Shi J.

Sequence number: 4

Author:

Date: 07-Oct-03 3:33:07 PM

Type: Note

Au: Pls update

Sequence number: 5

Author:

Date: 07-Oct-03 3:33:22 PM

Type: Note

Au: Pls provide year

Sequence number: 6

Author:

Date: 07-Oct-03 3:33:29 PM

Type: Highlight

Henderson

Sequence number: 7

Author:

Date: 07-Oct-03 3:35:21 PM

Type: Highlight

Doane

Sequence number: 8

Author:

Date: 07-Oct-03 3:35:37 PM

Type: Note

Au: Pls update 